\title{
Patterns of Care with a Positive Sentinel Node: Echoes of an Opportunity Missed
}

\author{
Monica Morrow, MD \\ Breast Service, Department of Surgery, Memorial Sloan-Kettering Cancer Center, New York, NY
}

In this issue of Annals of Surgical Oncology, Wasif and coauthors report the results of a survey of 537 American Society of Clinical Oncology (ASCO) members that shows only $23 \%$ of surgeons and medical oncologists, and only $15 \%$ of radiation oncologists, "always" perform an axillary dissection for the finding of micrometastases in the sentinel node (SN). ${ }^{1}$ This practice is contrary to ASCO guidelines that state axillary dissection is the standard management of micrometastases in the $\mathrm{SN}^{2}$ Documentation of a major deviation from guidelines is important, although it is possible to quibble with some of the specifics of this article. After all, the ASCO guidelines were published in 2005, and our knowledge regarding the $\mathrm{SN}$ procedure has increased exponentially since that time; it is not unreasonable to conclude that part of the reason the guidelines are not followed is because they are out of date. In addition, the wording of the survey question as "always" was unfortunate, since virtually nothing in breast cancer surgery is absolute. The use of the word "usually" might have provided a more accurate picture of clinical practice. However, to focus on these points is to miss the bigger questions: Why is there so much disagreement about appropriate practice? What have we learned about micrometastases and how should we deal with them?

Micrometastases are an unintended consequence of the more detailed tissue processing that is possible when examining a small number of sentinel lymph nodes rather than an entire axillary dissection specimen. Giuliano et al. first reported the increased frequency of identification of small metastases in 1995, with subsequent confirmation in other reports. ${ }^{3}$ Since that time, a key question for the clinical community has been: "Is axillary dissection

(C) Society of Surgical Oncology 2009

Published Online: 8 July 2009

M. Morrow, MD

e-mail: morrowm@mskcc.org necessary for SN micrometastases?" The benefit of axillary dissection is dependent on the likelihood of finding additional nodal metastases. Perhaps surprisingly, $12-20 \%$ of patients with isolated tumor cells or micrometastases in the $\mathrm{SN}$ included in two recent meta-analyses had additional nodal involvement, and in a substantial number of cases the additional metastases were macrometastases. ${ }^{4,5}$ These studies clearly make the point that a small amount of tumor in the SN does not indicate that disease in non-SNs will also be low volume. These results are clearly sufficient to justify axillary dissection if the finding of additional metastases will change the systemic therapy administered. An example is the patient with an ER/PR-positive, HER2negative, T1 tumor who might be considered suitable for endocrine therapy alone with a single micrometastases, but who, with additional micrometastases or a macrometastasis, would receive chemotherapy as well. More commonly, however, decisions about systemic therapy are not dependent on the presence of additional nodal metastases, leaving local control or a survival benefit as the rationale for axillary dissection. Many years ago, the National Surgical Adjuvant Breast and Bowel Project (NSABP) BO4 trial demonstrated that only about $40 \%$ of nodal metastases result in clinically evident axillary recurrence in patients treated with surgery alone. ${ }^{6}$ The tangent field radiotherapy (RT) that is part of breast-conserving therapy includes a substantial part of the low axilla and can be anticipated to reduce this risk further. This is borne out by clinical outcomes in patients with SN involvement who have not had an axillary dissection, where axillary recurrence is uncommon. ${ }^{7}$ As a result, it is difficult to argue that most women need an axillary dissection to maintain local control.

What about survival? The Early Breast Cancer Trialists Collaborative Group (EBCTCG) overview indicates that differences in local control of greater than $10-20 \%$ at 5 years of follow-up translate into significant differences in 
survival at 15 years. ${ }^{8}$ Although this concept was demonstrated for recurrences in the breast or on the chest wall postmastectomy, there is no reason to believe that recurrence in the axilla would not be equally important. However, to reach this level of difference in local recurrence by omitting axillary dissection, the risk of additional axillary nodal involvement would need to exceed $30 \%$, something that is infrequently seen in patients with micrometastatic disease in the SN. Based on these points, I must conclude that axillary dissection appears to be of little benefit to the majority of patients with micrometastases beyond providing additional prognostic information.

However, what is special about micrometastases? The $0.2-\mathrm{mm}$ threshold chosen to define a micrometastases is an arbitrary one, and the reproducibility of measurement of the size of nodal metastases is uncertain. ${ }^{9}$ The question asked here regarding the need for axillary dissection for micrometastases is equally applicable to macrometastases in the $\mathrm{SN}$, and it is particularly likely to be asked when macrometastases are not detected by intraoperative frozen section. At present, the decision about whether to proceed with an axillary dissection is made based on the risk of additional nodal metastases predicted by a variety of nomograms and on the level of patient and physician preference for or against axillary dissection. ${ }^{10,11}$ It would be preferable to have an actual answer to the question of whether elimination of axillary dissection was harmful to patients. The American College of Surgeons (ACOSOG) Z11 trial attempted to do just that by randomizing women with hematoxylin- and eosin-detected axillary nodal metastases to a completion dissection or no further axillary treatment. This study was opened in 1999 and closed in 2004 after accruing only 891 of the 1900 patients needed to identify a $5 \%$ or greater survival difference with axillary dissection. The Z11 trial was clearly ahead of its time. Many surgeons were unwilling to randomize patients because at that time, they were certain it was unethical to consider eliminating axillary dissection. According to the survey presented by Wasif et al., however, times have changed. ${ }^{1}$ As a result of our unwillingness as a clinical community to support the Z11 trial, we make the decision about axillary dissection based on retrospectively derived nomograms coupled with clinical judgment. This is a traditional surgical approach that we seem to be comfortable with, but it does not necessarily represent the best approach to controversies in management. The resolution of important clinical questions and the creation of paradigm shifts require clinical trials with the vision to address the big picture, and these trials are often the most difficult for both surgeons and their patients to participate in. It is worth thinking about how different breast-conserving therapy might look today if the NSABP B06 trial had not completed its accrual of a population of women of varying ages and tumor features. Although it is impossible to know for certain, I suspect that breast conservation would be considered an appropriate strategy for small favorable cancers, with mastectomy reserved for the remainder.

The appropriate management of the axilla in the era of SN biopsy in conjunction with the improved systemic therapy available today remains the big, unanswered question in the surgical therapy of breast cancer. As a community of surgeons, we failed to address this question the first time around; the consequences of that failure are evident every time we discuss this issue with our patients. Should the opportunity for participation in another trial arise, let us hope that we are all not only older at that moment, but wiser as well.

\section{REFERENCES}

1. Wasif N, Ye X, Giuliano AE. Survey of ASCO members on management of sentinel node micrometastases in breast cancer: variation in treatment recommendations according to specialty. Ann Surg Oncol. 2009. DOI: 10.1245/s10434-009-0549-7.

2. Lyman GH, Giuliano AE, Somerfield MR, Benson AB 3rd, Bodurka DC, Burstein HJ, et al. American Society of Clinical Oncology guideline recommendations for sentinel lymph node biopsy in early-stage breast cancer. J Clin Oncol. 2005;23:7703-20.

3. Giuliano AE, Dale PS, Turner RR, Morton DL, Evans SW, Krasne DL. Improved axillary staging of breast cancer with sentinel lymphadenectomy. Ann Surg. 1995;222:394-9 (discussion 399-401).

4. Cserni G, Gregori D, Merletti F, Sapino A, Mano MP, Ponti A, et al. Meta-analysis of non-sentinel node metastases associated with micrometastatic sentinel nodes in breast cancer. Br J Surg. 2004;91:1245-52.

5. van Deurzen CM, de Boer M, Monninkhof EM, Bult P, van der Wall E, Tjan-Heijnen VC, et al. Non-sentinel lymph node metastases associated with isolated breast cancer cells in the sentinel node. J Natl Cancer Inst. 2008;100:1574-80.

6. Fisher B, Redmond C, Fisher ER, Bauer M, Wolmark N, Wickerham DL, et al. Ten-year results of a randomized clinical trial comparing radical mastectomy and total mastectomy with or without radiation. $N$ Engl J Med. 1985;312:674-81.

7. Park J, Fey JV, Naik AM, Borgen PI, Van Kee KJ, Cody HS 3rd. A declining rate of completion axillary dissection in sentinel lymph node-positive breast cancer patients is associated with the use of a multivariate nomogram. Ann Surg. 2007;245:462-8.

8. Clarke M, Collins R, Darby S, Davies C, Elphinstone P, Evans E, et al. Effects of radiotherapy and of differences in the extent of surgery for early breast cancer on local recurrence and 15-year survival: an overview of the randomised trials. Lancet. 2005;366:2087-106.

9. Greene FL, Page DL, Fleming ID, Fritz A, Balch CM, Haller DG, et al. editors. AJCC Cancer Staging Manual. 6th ed., New York: Springer-Verlag, 2002:221-40.

10. Gur AS, Unal B, Johnson R, Ahrendt G, Bonaventura M, Gordon $\mathrm{P}$, et al. Predictive probability of four different breast cancer nomograms for nonsentinel axillary lymph node metastasis in positive sentinel node biopsy. J Am Coll Surg. 2009;208:229-35.

11. Van Zee KJ, Manasseh DM, Bevilacqua JL, Boolbol SK, Fey JV, Tan LK, et al. A nomogram for predicting the likelihood of additional nodal metastases in breast cancer patients with a positive sentinel node biopsy. Ann Surg Oncol. 2003;10:1140-51. 